\title{
D- $\pi$-A Dye System Containing Cyano-Benzoic Acid as Anchoring Group for Dye-Sensitized Solar Cells
}

\author{
Masataka Katono, ${ }^{+}$Takeru Bessho, ${ }^{\dagger}$ Sheng Meng, ${ }^{\ddagger}$ Robin Humphry-Baker, ${ }^{\dagger}$ Guido Rothenberger, ${ }^{\dagger}$ \\ Shaik M. Zakeeruddin, ${ }^{+}$Efthimios Kaxiras, ${ }^{\S}$ and Michael Grätzel ${ }^{*,+}$ \\ ${ }^{\dagger}$ Laboratory for Photonics and Interfaces, Institute of Chemical Sciences and Engineering, Swiss Federal Institute of Technology, \\ CH-1015 Lausanne, Switzerland \\ ${ }^{\ddagger}$ Beijing National Laboratory for Condensed Matter Physics, and Institute of Physics, Chinese Academy of Sciences, \\ 100190 Beijing, China \\ ${ }^{\S}$ Department of Physics and School of Engineering and Applied Sciences, Harvard University, Cambridge, Massachusetts 02138, \\ United States
}

ABSTRACT: A D- $\pi$-A dye (KM-1) incorporating cyanobenzoic acid as a new acceptor/anchoring group has been synthesized for dye-sensitized solar cells (DSCs) with a high molar extinction coefficient of $66700 \mathrm{M}^{-1} \mathrm{~cm}^{-1}$ at $437 \mathrm{~nm}$. Theoretical calculations show that the hydrogen bond between $-\mathrm{CN}$ and surface hydroxyl leads to the most stable configuration on the surface of $\mathrm{TiO}_{2}$. In addition, the adsorption of the dye on $\mathrm{TiO}_{2}$ follows a Brunauer-Emmett-Teller (BET) isotherm. Multilayer adsorption of KM-1 on $\mathrm{TiO}_{2}$ seems to take place particularly at higher dye concentrations. DSC device using KM-1 reached a maximum incident photon-to-current conversion efficiency (IPCE) of $84 \%$, with a solar to electric power conversion efficiency (PCE) of $3.3 \%$ at AM1.5 G illumination $\left(100 \mathrm{~mW} \mathrm{~cm} \mathrm{~cm}^{-2}\right)$. This new type of anchoring group paves a way to design new dyes that combine good visible light harvesting with strong binding to the metal oxide surface.
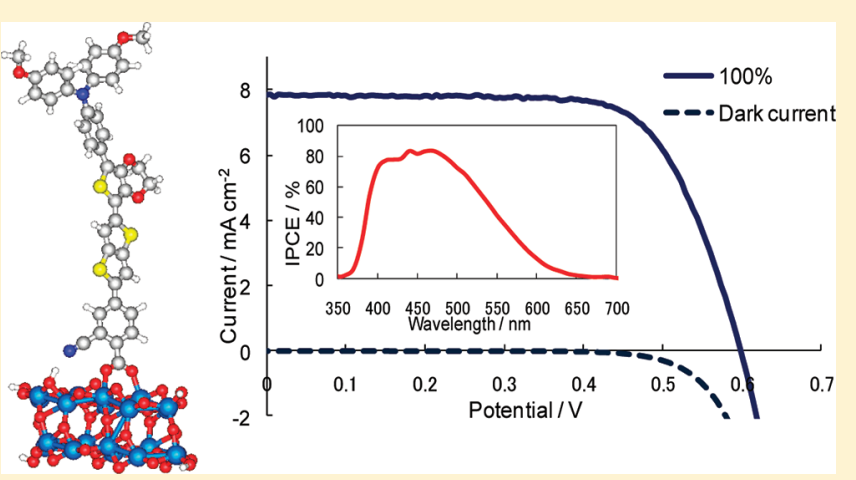

\section{INTRODUCTION}

Dye-sensitized solar cells (DSCs) have attracted much attention in recent years due to their potential advantages of low cost, ease of production, flexibility, and transparency relative to conventional crystalline silicon solar cells. The photosensitizer is a key component of the DSC, being responsible for the capture of sunlight and generation of electric charges. State-of-the-art DSCs using ruthenium sensitizers exhibit record solar to electricity power conversion efficiencies (PCEs) of over 11-12\% under AM $1.5 \mathrm{G}$ irradiation. ${ }^{1,2}$ The performance of DSCs based on metal-free organic sensitizers has also recently been improved, with PCE of up to $10 \%$ values having been reported. ${ }^{3-7}$ Most efficient metalfree organic sensitizers are D- $\pi$-A systems, composed of donor, $\pi$-conjugated spacer, and acceptor/anchoring groups. Organic dyes have advantages as photosensitizers due to their high molar extinction coefficients, tuning of absorption wavelength, and relatively facile design and synthesis. Several synthetic strategies for the development of organic sensitizers have been introduced to enhance their performance. These include the incorporation of various functional groups, such as fluorene, coumarin, indoline, cyanine, perylene, triarylamine, and xanthenes, to the donor part. ${ }^{8,9}$ A successful approach was to add a $\pi$-conjugated linker such as thiophene, thienothiophene, 3,4-ethylenedioxy-thiophene (EDOT), benzo[1,2,5]-thiadiazole, $p$-phenylene vinylene, and quinoline derivatives for the improvement of efficiency and stability. ${ }^{8,9}$ On the contrary, the acceptor/anchoring group has been much less investigated, with cyanoacrylic acid being most widely employed to attach the organic dye to the surface of the titania nanocrystals. In this paper, we report on a novel organic sensitizer, coded KM- 1 , exhibiting extended $\pi$-conjugation at the acceptor/anchoring group. As shown in Figure 1, the KM-1 contains alkoxytriphenylamine as a donor, a binary $\pi$-conjugated spacer composed of a thienothiophene, an EDOT unit, and a cyano-benzoic acid as the novel acceptor/anchoring group. This way we created directionality in the molecule to inject excited electron into the $\mathrm{TiO}_{2}$ conduction band.

\section{EXPERIMENTAL SECTION}

Materials. Thienothiophene $\mathbf{1}$ was prepared as previously reported. ${ }^{3}$ All chemicals and solvents were purchased from commercial sources and used without further purification. The methyl 4-chloro-2-cyanobenzoate was obtained from 3B Scientific Corporation.

Synthesis of 4-\{7-(5-Bromothieno[3,2-b]thiophen-2-yl)2,3-dihydrothieno[3,4-b][1,4]dioxin-5-yl\}-N,N-bis(4-hexyl-
Received: August 9, 2011
Revised: October 11, 2011
Published: October 14, 2011 


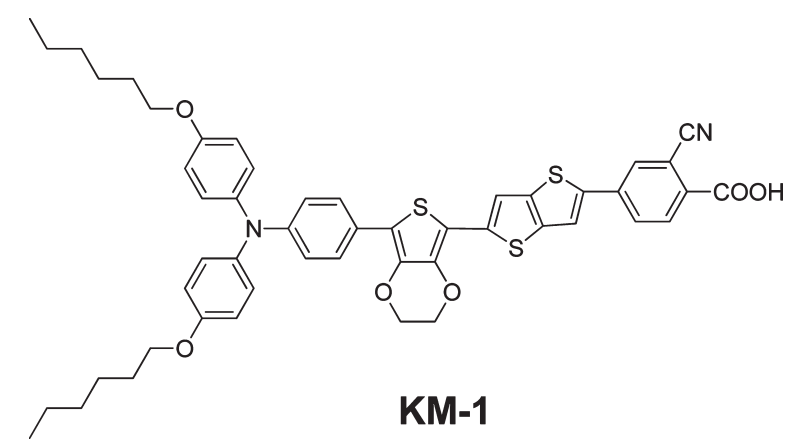

Figure 1. Molecular structure of the KM-1 dye.

oxyphenyl)aniline (2). A solution of $1(0.543 \mathrm{~g}, 0.750 \mathrm{mmol})$ in $\mathrm{N}, \mathrm{N}^{\prime}$-dimethylformamide (DMF; $7 \mathrm{~mL}$ ) at $0{ }^{\circ} \mathrm{C}$ was charged with a solution of $\mathrm{N}$-bromosuccinimide $(0.134 \mathrm{~g}, 0.750 \mathrm{mmol})$ in DMF $(5 \mathrm{~mL})$. After $3 \mathrm{~h}$ stirring at $0{ }^{\circ} \mathrm{C}$, crushed ice was added and the mixture solution was extracted with dichloromethane $(3 \times 12 \mathrm{~mL})$. The combined organic layers were washed with water $(3 \times 60 \mathrm{~mL})$ and dried over anhydrous $\mathrm{MgSO}_{4}$. The solvent was removed and the residue was purified on a silica gel column with EtOAc/hexane (1/100, v/v) to obtain 2 in $60 \%$ yield $(0.358 \mathrm{~g}) .{ }^{1} \mathrm{HNMR}$ (DMSO- $\left.d_{6}, 400 \mathrm{MHz}\right): \delta 0.88$ $(\mathrm{t}, J=7.2 \mathrm{~Hz}, 6 \mathrm{H}), 1.31(\mathrm{~m}, 8 \mathrm{H}), 1.41(\mathrm{~m}, 4 \mathrm{H}), 1.71(\mathrm{~m}, 4 \mathrm{H}), 3.93(\mathrm{t}, J=$ $6.4 \mathrm{~Hz}, 4 \mathrm{H}), 4.37(\mathrm{~m}, 2 \mathrm{H}), 4.42(\mathrm{~m}, 2 \mathrm{H}), 6.78(\mathrm{~d}, J=8.8 \mathrm{~Hz}, 2 \mathrm{H}), 6.89$ $(\mathrm{d}, J=8.8 \mathrm{~Hz}, 4 \mathrm{H}), 7.01(\mathrm{~d}, J=8.8 \mathrm{~Hz}, 4 \mathrm{H}), 7.47(\mathrm{~d}, J=8.8 \mathrm{~Hz}, 2 \mathrm{H}), 7.51$ (s, $1 \mathrm{H}), 7.61(\mathrm{~s}, 1 \mathrm{H})$. MS (ESI): $m / z$ calcd for $\mathrm{C}_{42} \mathrm{H}_{42} \mathrm{BrNO}_{4} \mathrm{~S}_{3}$ : 803.16. Found: $803.16\left[\mathrm{M}^{+}\right]$.

Synthesis of Methyl 2-Cyano-4-(4,4,5,5-tetramethyl-1,3,2dioxaborolan-2-yl)benzoate (4). A $100 \mathrm{~mL}$ flask with a magnetic stirring bar, a septum inlet, and a condenser was charged with $\mathrm{Pd}(\mathrm{dba})_{2}$ $(0.17 \mathrm{~g}, 0.3 \mathrm{mmol})$ and tricyclohexylphosphine $(0.20 \mathrm{~g}, 0.72 \mathrm{mmol})$ under nitrogen. Dioxane $(35 \mathrm{~mL})$ was added, and the resulting mixture was then stirred for $30 \mathrm{~min}$ at room temperature. Bis(pinacolato)diboron (2.79 g, $11 \mathrm{mmol}), \mathrm{KOAc}(1.47 \mathrm{~g}, 15 \mathrm{mmol})$, and 3 (1.96 g, 10 $\mathrm{mmol}$ ) were added successively. After being stirred at $80^{\circ} \mathrm{C}$ for $19 \mathrm{~h}$, the reaction mixture was treated with water $(30 \mathrm{~mL})$. The product was extracted with toluene, washed with brine, and dried over $\mathrm{MgSO}_{4}$. Removal of the solvent followed by trituration with methanol gave 4 as white solid in $45 \%$ yield $(1.29 \mathrm{~g}) .{ }^{1} \mathrm{H} \mathrm{NMR}\left(\mathrm{CDCl}_{3}, 400 \mathrm{MHz}\right): \delta 1.36$ $(\mathrm{s}, 12 \mathrm{H}), 4.00(\mathrm{~s}, 3 \mathrm{H}), 8.05(\mathrm{~d}, J=7.6 \mathrm{~Hz}, 1 \mathrm{H}), 8.10(\mathrm{~d}, J=7.6 \mathrm{~Hz}, 1 \mathrm{H})$, $8.22(\mathrm{~s}, 1 \mathrm{H})$.

Synthesis of 4- $\{5-\{7-\{4-\{$ Bis(4-hexyloxyphenyl)amino $\}-$ phenyl\}-2,3-dihydrothieno[3,4-b][1,4]dioxin-5-yl\}thieno[3,2-b]thiophen-2-yl\}-2-cyanobenzoic Acid (KM-1). 2 (0.132 g, $0.164 \mathrm{mmol}), 4$ (0.0566 g, $0.197 \mathrm{mmol}), \mathrm{K}_{2} \mathrm{CO}_{3}(0.099 \mathrm{~g}, 0.716 \mathrm{mmol})$, and $\mathrm{Pd}\left(\mathrm{PPh}_{3}\right)_{4}(0.024 \mathrm{~g}, 0.02 \mathrm{mmol})$ were dispersed in a mixture of tetrahydrofuran $(10 \mathrm{~mL})$ and water $(2 \mathrm{~mL})$. After the reaction was performed at $80^{\circ} \mathrm{C}$ for $68 \mathrm{~h}$, the mixture was diluted with water $(20 \mathrm{~mL})$ and $\mathrm{CH}_{2} \mathrm{Cl}_{2}(30 \mathrm{~mL})$ and then acidified with $1 \mathrm{M} \mathrm{HCl}$ under cooling (at $0{ }^{\circ} \mathrm{C}$ ) condition. The organic layer was separated and subsequently dried over anhydrous $\mathrm{MgSO}_{4}$. The solvent was removed and the residue was purified on a silica gel column with $\mathrm{MeOH} / \mathrm{CH}_{2} \mathrm{Cl}_{2}(1 / 5, \mathrm{v} / \mathrm{v})$ to obtain KM- 1 as brown solid in 50\% yield $(0.071 \mathrm{~g}) .{ }^{1} \mathrm{H}$ NMR (DMSO- $d_{6}$, $400 \mathrm{MHz}): \delta 0.88(\mathrm{t}, J=7.2 \mathrm{~Hz}, 6 \mathrm{H}), 1.31(\mathrm{~m}, 8 \mathrm{H}), 1.41(\mathrm{~m}, 4 \mathrm{H}), 1.70$ $(\mathrm{m}, 4 \mathrm{H}), 3.93(\mathrm{t}, J=6.4 \mathrm{~Hz}, 4 \mathrm{H}), 4.37(\mathrm{~m}, 2 \mathrm{H}), 4.44(\mathrm{~m}, 2 \mathrm{H}), 6.78(\mathrm{~d}, J=$ $8.8 \mathrm{~Hz}, 2 \mathrm{H}), 6.89(\mathrm{~d}, J=8.8 \mathrm{~Hz}, 4 \mathrm{H}), 7.00(\mathrm{~d}, J=8.8 \mathrm{~Hz}, 4 \mathrm{H}), 7.47$ (d, $J=$ $8.8 \mathrm{~Hz}, 2 \mathrm{H}), 7.55$ (s, 1H), 7.83 (d, $J=8.0 \mathrm{~Hz}, 1 \mathrm{H}), 8.03(\mathrm{~m}, 3 \mathrm{H}) . \mathrm{MS}$ (ESI): $m / z$ calcd for $\mathrm{C}_{50} \mathrm{H}_{48} \mathrm{~N}_{2} \mathrm{O}_{6} \mathrm{~S}_{3}: 868.27$. Found: $868.32\left[\mathrm{M}^{+}\right]$.

Differential Pulse Voltammetry (DPV) Measurement. KM-1 in a DMF solution containing tetrabutylammonium hexafluorophosphate $(0.1 \mathrm{M})$ was used as a supporting electrolyte. DPV was measured with glassy carbon as the working electrode and $\mathrm{Pt}$ as the counter
Scheme 1. Synthetic Route of the KM-1 Dye

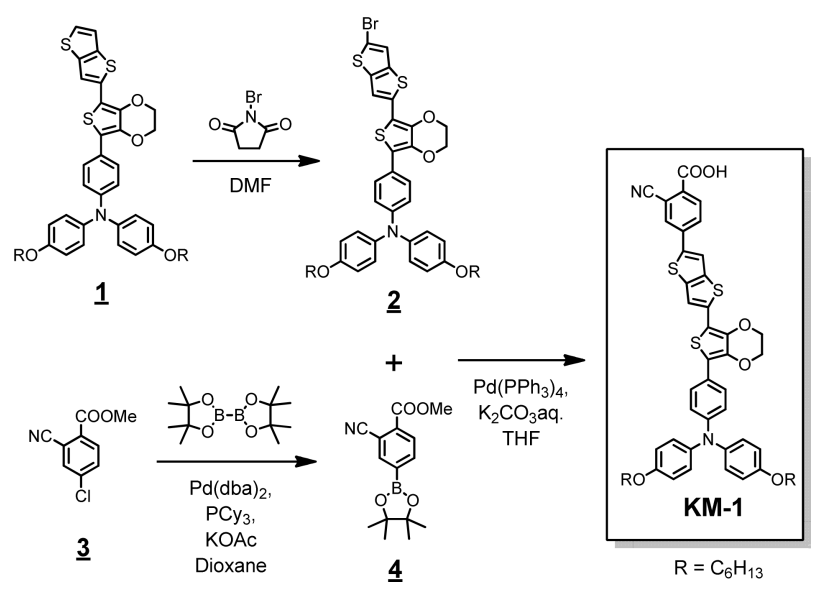

electrode under Ar atmosphere, and the redox potentials were calibrated with ferrocene as the internal reference.

Cell Fabrication. A state-of-the art double layer mesoporous $\mathrm{TiO}_{2}$ layer $(8.2 \mu \mathrm{m}$ of $20 \mathrm{~nm}$ particle; DSL $18 \mathrm{NR}-\mathrm{T}$, DYESOL) plus $4.5 \mu \mathrm{m}$ of $400 \mathrm{~nm}$ light scattering particles (HPW-400NRD, CCIC)) was employed on FTO conducting glass (Solar-4 mm, Nippon Sheet Glass Co., Ltd.). The double layer $\mathrm{TiO}_{2}$ film was sensitized by immersing it into a $\mathrm{KM}-1$ solution $(0.1 \mathrm{mM})$ in DMF for $16 \mathrm{~h}$ at room temperature. The composition of the electrolyte is $1.0 \mathrm{M} \mathrm{1,3-dimethylimidazolium} \mathrm{iodide,}$ $50 \mathrm{mM} \mathrm{LiI}, 30 \mathrm{mM} \mathrm{I}_{2}, 0.5 \mathrm{M}$ tert-butylpyridine, and $0.1 \mathrm{M}$ guanidinium thiocyanate in a mixture of acetonitrile and valeronitrile $(85 / 15, \mathrm{v} / \mathrm{v})$. A platinized FTO conducting glass (LOF TECH 7, Pilkington) was used as counter electrode. The spectral distribution of the light source simulated the AM 1.5G solar irradiation (Xe 450W/K113 (filter) with a mismatch less than $4 \%$ ). The device active area is $0.16 \mathrm{~cm}^{2}$, covered with black tape mask for excluding any diffused light. An antireflection film (ARCTOP, Mihama Co.) was attached on the photoanode side.

Calculations. First-principles calculations were performed within the framework of density functional theory (DFT) for structure optimization and TDDFT for excited states and optical absorption, using SIESTA ${ }^{10}$ and Gaussian ${ }^{11}$ packages. For structure, we used pseudopotentials of the Troullier-Martins type to model the atomic cores, the PBE form of the exchange-correlation functional, and a local basis set of double-polarized orbitals (19 orbitals for Ti; 13 orbitals for $\mathrm{C}, \mathrm{N}, \mathrm{O}$ and $\mathrm{S} ; 5$ orbitals for $\mathrm{H}$ ). An auxiliary real space grid equivalent to a plane-wave cutoff of 100 Ry was used. A molecular structure was considered fully relaxed when the magnitude of forces on the atoms was smaller than $0.02 \mathrm{eV} /$ Á. Optical absorptions are extracted from TDDFT simulations within linear response theory and using a longrange corrected functional $\omega \mathrm{B} 97 \mathrm{X} .^{12}$ We used the $6-31 \mathrm{G}(\mathrm{d})$ basis set. The impact of geometry optimization procedures and basis- sets on atomic structure and excitation energies are shown to be negligible.

\section{RESULTS AND DISCUSSION}

The KM-1 dye was synthesized in three steps as shown in Scheme 1. 1 was treated with $N$-bromosuccinimide (NBS) to yield bromothienothiophene 2 . The cyano-benzoic acid anchoring group was synthesized by the palladium-catalyzed Suzuki coupling reaction of 2 , pinacolate 4 , and tetrakis triphenylphosphine palladium to yield finally the KM-1 sensitizer. Synthetic details are given in the Experimental Section.

As shown in Figure 2, the electronic absorption spectrum (CARY 5, Varian) of the KM-1 dissolved in DMF exhibits a strong absorption band at $437 \mathrm{~nm}$ and a weaker band appearing 


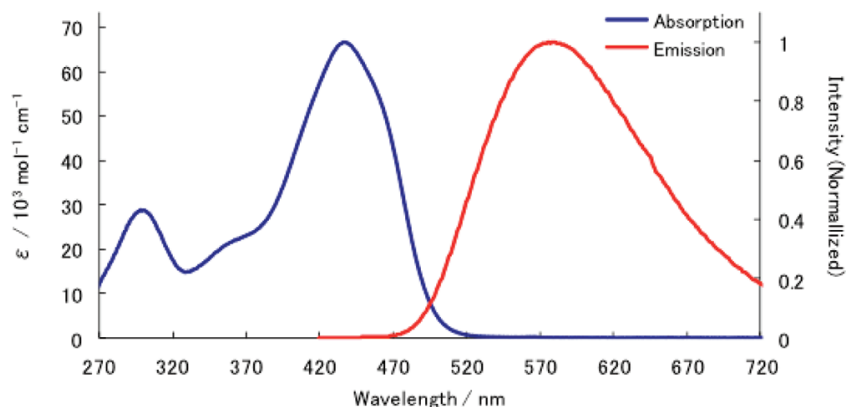

Figure 2. Electronic absorption (blue line) and emission (red line) spectrum of the KM-1 dissolved in DMF.

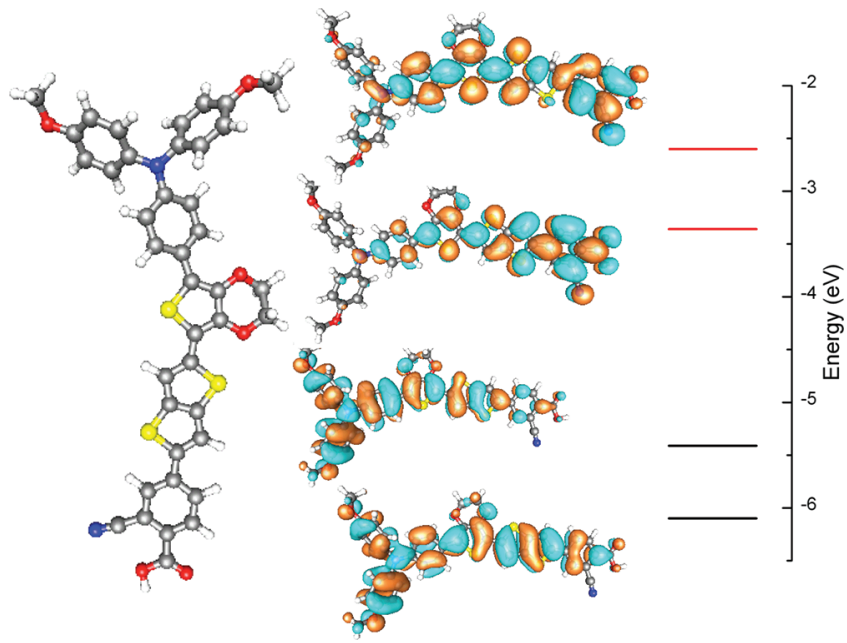

Figure 3. Optimized geometry of model KM-1 dye, corresponding wave functions at the isosurface level of $0.03 \mathrm{e} / \AA^{3}$ for HOMO-1, HOMO, LUMO, and LUMO+1 orbitals (from bottom to up) and energy levels from DFT/B3LYP. The levels are downshifted by $0.31 \mathrm{eV}$ to match HOMO to the experimental value $(-5.41 \mathrm{eV})$.

at $300 \mathrm{~nm}$. The molar extinction coefficients of the peaks at 300 and $437 \mathrm{~nm}$ are 28800 and $66700 \mathrm{M}^{-1} \mathrm{~cm}^{-1}$, respectively. The high molar extinction coefficient of this dye allows us to use thinner $\mathrm{TiO}_{2}$ films as photoanodes in the fabrication of DSCs. The peak absorption of KM-1 on the $\mathrm{TiO}_{2}$ film is shifted by about $10 \mathrm{~nm}$ to shorter wavelength compared to that in solution, which may be due to $\mathrm{H}$ aggregation of dye on the surface of $\mathrm{TiO}_{2}$. A broadening of the absorption tail to longer wavelength is also observed improving the photoresponse. The emission spectrum was measured using a $480 \mathrm{~nm}$ excitation wavelength and was photometrically corrected (Fluorolog 3, HORIBA).

DPV was used to determine the redox potentials of the KM-1 dye. Reversible oxidation and reduction waves were observed at $0.31 \mathrm{~V}$ and $-2.14 \mathrm{~V}$ ( $\mathrm{vs} \mathrm{Fc}^{+} / \mathrm{Fc}$ ), respectively. The energy offset of the LUMO $(-3.1 \mathrm{eV})$ of the dye molecule with respect to the titania conduction band edge $(-4.0 \mathrm{eV})$ provides the thermodynamic driving forces for charge separation. In this case, the LUMO and CB offset is $0.9 \mathrm{eV}$; by reducing this gap, one can red-shift the absorption spectra to absorb more visible light and enhance the photoconversion efficiency. The energy offset of the $\mathrm{HOMO}(-5.41 \mathrm{eV})$ is relative to that of the iodide $(-4.8 \mathrm{eV})$. The fact that $>80 \%$ incident photon-to-current conversion efficiency (IPCE) was obtained with the DSCs employing the $\mathrm{KM}-1$ dye proves that $0.61 \mathrm{eV}$ difference between the HOMO
Table 1. Theoritical Excited-State TD-FDT/ $\omega$ B97X Calculation of KM-1 Dye, and Comparison with Experiment ${ }^{a}$

\begin{tabular}{ccccc}
$n$ & $E(\mathrm{eV}, \mathrm{nm})$ & $f$ & composition & expt \\
1 & $2.89(429)$ & 2.285 & $43 \% \mathrm{H} \rightarrow \mathrm{L} ; 25 \% \mathrm{H}-1 \rightarrow \mathrm{L}$ & $440 \mathrm{~nm}$ \\
2 & $3.74(331)$ & 0.121 & $29 \% \mathrm{H} \rightarrow \mathrm{L}+1 ; 24 \% \mathrm{H}-1 \rightarrow \mathrm{L}$ & $350 \mathrm{~nm}$ \\
3 & $4.30(288)$ & 0.200 & $44 \% \mathrm{H}-1 \rightarrow \mathrm{L}+1$ & $300 \mathrm{~nm}$ \\
${ }^{a} E$ & calculated absorption energy, $f=$ oscillator's strength, and expt $=$ \\
\multicolumn{5}{l}{ experimental result. H stands for HOMO, and L for LUMO. }
\end{tabular}
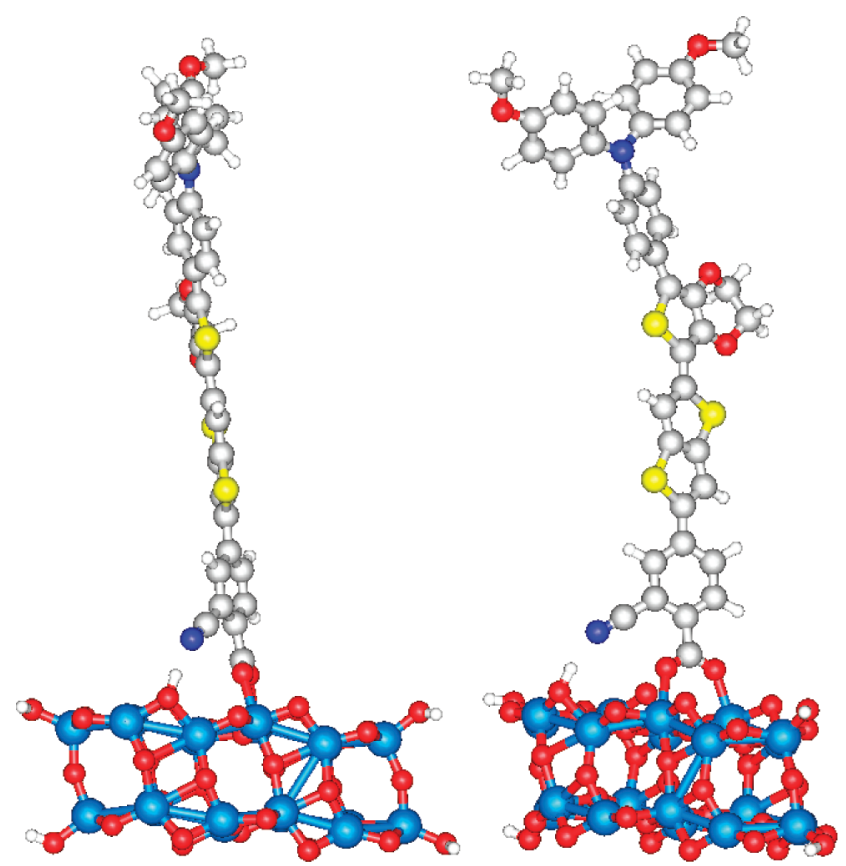

Figure 4. Side and front views of KM-1 adsorption on a $\mathrm{TiO}_{2}$ nanoparticle.

and the redox potential of the electrolyte is sufficient to regenerate the dye, in keeping with earlier observations.

Figure 3 shows the optimized molecular structure and frontier molecular orbitals of KM-1 (for simplicity, we consider $R=$ $\mathrm{CH}_{3}$ ). The molecule retains perfect planar geometry, with only $-\mathrm{C}_{2} \mathrm{H}_{4}$ in EDOT and the donor tails slightly protruding from the molecular plane. Wave functions are mainly distributed around the donor and the acceptor group for the occupied (HOMO-1 and $\mathrm{HOMO}$ ) and unoccupied orbitals (LUMO, LUMO+1), respectively, favoring fast electron-hole separation upon photoexcitation. We also compared the energy levels at the B3LYP level to experiment: after an empirical downshift of $0.31 \mathrm{eV}$, calculated orbital levels match experimental ones nicely; see Figure 3.

To gain more insight into its optical property, we also calculated the absorption spectrum of KM-1 using TDDFT with a long-ranged corrected functional ( $\omega$ B97X) in DMF solution. The results are summarized in Table 1. Low-energy excitations agree well with experimental data and mainly come from transitions involving HOMO-1, HOMO, LUMO, and LUMO+1 orbitals.

A particular advantage of cyano-benzoic acid as an acceptor in $\mathrm{KM}-1$ dye structure is that it strongly enhances dye binding onto $\mathrm{TiO}_{2}$ surfaces compared to cyano-acrylic acid. We investigated the binding geometries of $\mathrm{KM}-1$ on anatase $\mathrm{TiO}_{2}$ (101) using 


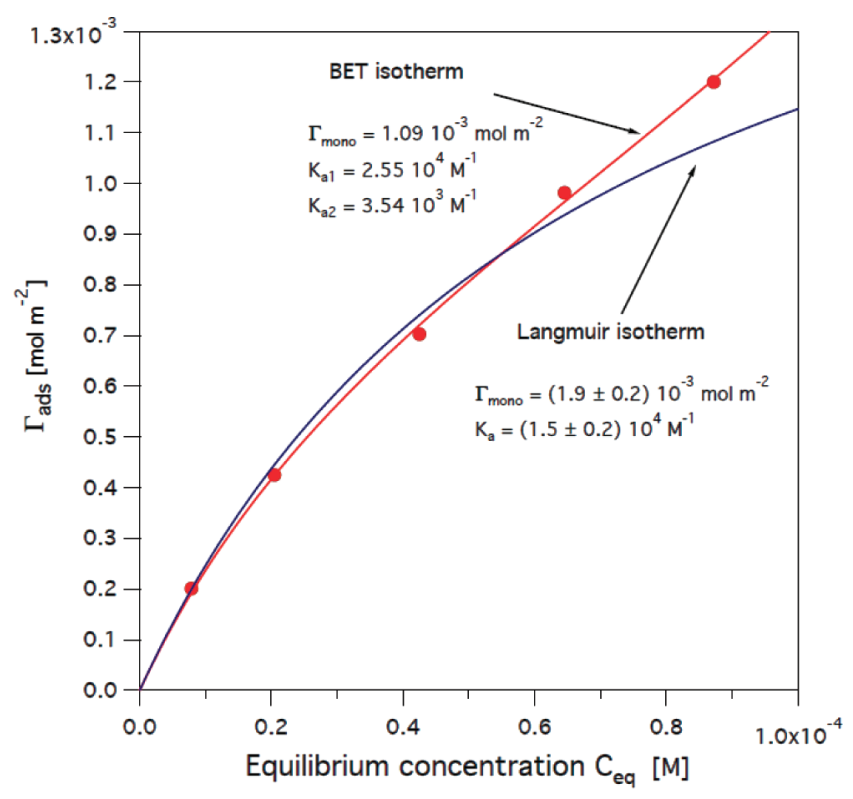

Figure 5. Langmuir isotherm curve (blue) and BET isotherm curve (red).

DFT. Among several stable-binding configurations, the one with a bidentate bond and a hydrogen bond between - $\mathrm{CN}$ and surface hydroxyl (originating from dissociated carboxylic acid upon adsorption) is the most stable configuration with a binding energy of $1.52 \mathrm{eV}$ (see Figure 4 ). The bond lengths are $d_{\mathrm{Ti} 1-\mathrm{O} 1}=$ $2.146 \AA, d_{\mathrm{Ti} 2-\mathrm{O} 2}=2.162 \AA$, and $d_{\mathrm{CN}} \cdots_{\mathrm{HO}}=1.80 \AA$. Since three bonds are formed, which is not possible in cyano-acrylic acid anchoring groups, the KM-1 is strongly stabilized on $\mathrm{TiO}_{2}$.

The adsorption equilibrium of KM-1 on $\mathrm{TiO}_{2}$ was also investigated. Figure 5 shows the surface concentration $\Gamma_{\text {ads }}$ of the adsorbed dye as a function of the equilibrium concentration $C_{\mathrm{eq}}$ in the DMF solution. $\Gamma_{\mathrm{ads}}$ is calculated from the amount of dye desorbed from the $\mathrm{TiO}_{2}$ film using a $0.05 \mathrm{M}$ tetrabutylammonium hydroxide solution in DMF and from the projected area of the $\mathrm{TiO}_{2}$ film $\left(0.16 \mathrm{~cm}^{2}\right)$. The experimental $\Gamma_{\mathrm{ads}}$ versus $C_{\mathrm{eq}}$ data was fitted to a Langmuir isotherm (eq 1) and to a Brunauer-Emmett-Teller (BET) isotherm (eq 2).

$$
\begin{aligned}
\Gamma_{\mathrm{ads}} & =\frac{\Gamma_{\mathrm{mono}} K_{\mathrm{a}} C_{\mathrm{eq}}}{1+K_{\mathrm{a}} C_{\mathrm{eq}}} \\
\Gamma_{\mathrm{ads}} & =\frac{\Gamma_{\mathrm{mono}} K_{\mathrm{a} 1} C_{\mathrm{eq}}}{\left\{1+\left(K_{\mathrm{a} 1}-K_{\mathrm{a} 2}\right) C_{\mathrm{eq}}\right\}\left(1-K_{\mathrm{a} 2} C_{\mathrm{eq}}\right)}
\end{aligned}
$$

Here, $\Gamma_{\text {mono }}$ is the surface concentration of the dye that corresponds to monolayer coverage of the interface. In the Langmuir equation, which assumes that a single layer can cover the surface at most, $K_{\mathrm{a}}$ is the adsorption equilibrium constant. By contrast, the BET model allows for multilayer adsorption. $K_{\mathrm{a} 1}$ is the equilibrium constant for adsorption of the dye on the solid, and $K_{\mathrm{a} 2}$ is the equilibrium constant for adsorption on sites that are already occupied by adsorbed dye molecules. The best-fit parameters obtained for these variables are given as insets in Figure 5.

With an estimated roughness factor of 1060 for the $\mathrm{TiO}_{2}$ film, an effective area per KM-1 dye molecule of $90 \AA^{2}$ is calculated from the value of $\Gamma_{\text {mono }}$ in the Langmuir isotherm case. The

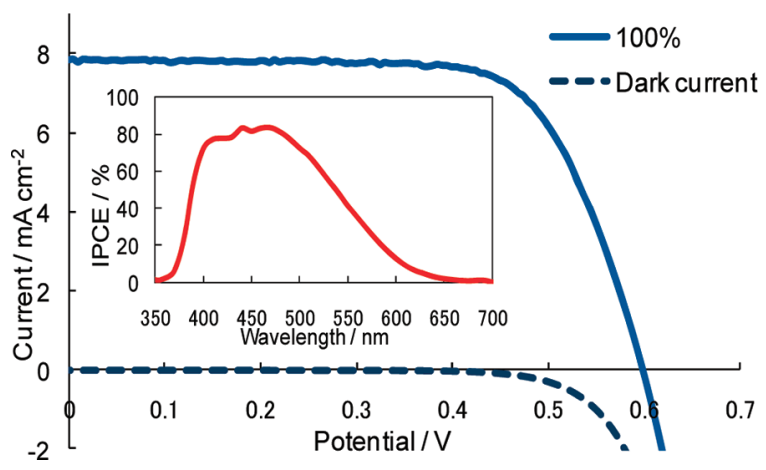

Figure 6. $I-V$ characteristics of a DSC sensitized with KM-1 measured under AM 1.5 G sunlight at 100\% sunlight (blue), and incident photon to current conversion efficiency curve (red).

corresponding value obtained in the BET case is $160 \AA^{2}$. From molecular modeling, an approximate area of the cross section of the molecule is $110 \AA^{2}$ (Figure 4), which is larger than the area predicted from the fitting to the Langmuir isotherm. This observation, together with the fact that the BET isotherm leads to a better fit to the experimental data, particularly at higher concentrations, seems to indicate that multilayer adsorption of $\mathrm{KM}-1$ on $\mathrm{TiO}_{2}$ takes place.

Preliminary photovoltaic tests were conducted to evaluate the potential of KM-1 as a sensitizer in DSC. The photocurrent action spectrum of DSC with the KM-1 as sensitizer is shown in Figure 6 as an inset. The IPCE exceeds $70 \%$ from 390 to $510 \mathrm{~nm}$, reaching the maximum of $84 \%$ at $470 \mathrm{~nm}$. This high value shows efficient electron injection from the KM-1 excited state to the conduction band of the $\mathrm{TiO}_{2}$ due to sufficiently strong electronic coupling between cyano-benzoic acid and $3 \mathrm{~d}$ orbitals of $\mathrm{TiO}_{2}$. The broadened and red-shifted IPCE spectrum of the KM-1 in Figure 6, compared to the absorption spectrum of the KM-1 in solution, can be ascribed to the influence of the double layer at the $\mathrm{TiO}_{2} /$ electrolyte interface and/or to aggregation of the dye. As shown in Figure 6, the short-circuit photocurrent density $\left(J_{\mathrm{sc}}\right)$, open-circuit photovoltage $\left(V_{\mathrm{oc}}\right)$, and fill factor $(\mathrm{FF})$ of DSC at AM1.5G conditions $\left(100 \mathrm{~mW} \mathrm{~cm}^{-2}\right)$ are $7.8 \mathrm{~mA} \mathrm{~cm}^{-2}, 600 \mathrm{mV}$, and 0.705 , respectively, yielding photo conversion efficiency $(\eta)$ of $3.3 \%$.

\section{CONCLUSIONS}

In summary, we designed and synthesized a novel high molar extinction coefficient organic sensitizer, KM-1, with cyanobenzoic acid as an acceptor/anchoring group. The theoretical calculations show that the hydrogen bond between $-\mathrm{CN}$ and surface hydroxyl is the most stable configuration on the surface of $\mathrm{TiO}_{2}$. The adsorption of the dye follows the BET isotherm. The DSC device with KM-1 reached the maximum IPCE of 84\%, with a photoconversion efficiency of $3.3 \%$ at AM1.5 G illumination $\left(100 \mathrm{~mW} \mathrm{~cm}^{-2}\right)$. This shows that cyano-benzoic acid is a potential unit as a new acceptor/anchoring group. We are currently investigating this novel anchoring group linked to high molar extinction dyes that shift the spectral response of the cell to the red region of the solar spectrum, in order to enhance the device performance. In KM-1 dye, the driving force for the electron injection from the excited state of the sensitizer into the $\mathrm{TiO}_{2}$ conduction band is excessive. Hence, there is a room for red-shifting the absorption of the sensitizer by lowering its 
LUMO level without sacrificing the yield of injection. The spectral response could be broadened or red-shifted by varying the position of cyano group on the benzoic acid or by substituting the $\mathrm{COOH}$ group at the meta position of benzene instead of the para position.

\section{AUTHOR INFORMATION}

\section{Corresponding Author}

*E-mail: michael.graetzel@epfl.ch. Telephone: +41 (0) 21693 31 12. Fax: +41 (0) 216936100.

\section{ACKNOWLEDGMENT}

We thank Swiss National Science Foundation and EU SPICooperation, Collaborative project INNOVASOL, FP7-NMP3SL-2009-227057, Grant agreement Number 22 for the financial support. S.M. acknowledges support from hundred-talent program of CAS and NSFC (grant 11074287). We are grateful to Dr. Tsuguo Koyanagi from JGC C\&C (Japan), Dyesol (Australia), and Nippon Sheet Glass Co., Ltd, Mihama Co., for providing the $400 \mathrm{~nm}$ sized $\mathrm{TiO}_{2}$ particles, the $20 \mathrm{~nm}$ particles (DSL 18NR-T), the FTO glass, and antireflection layer, respectively. We thank Dr. Etienne Baranoff and Dr. Yum Jun-Ho for fruitful discussions. M.K. is grateful to Kureha Cooperation for scholarship support.

\section{REFERENCES}

(1) Grätzel, M. Acc. Chem. Res. 2009, 42, 1788-1798.

(2) (a) Chen, C.; Wang, M.; Li, J.; Pootrakulchote, N.; Alibabaei, L.; Ngoc-le, C.; Decoppet, J.; Tsai, J.; Grätzel, C.; Wu, C.; Zakeeruddin, S. M.; Grätzel, M. ACS Nano 2009, 3, 3103. (b) Gao, F.; Wang, Y.; Shi, D.; Zhang, J.; Wang, M.; Jing, X.; Humphry Baker, R.; Wang, P.; Zakeeruddin, S. M.; Grätzel, M. J. Am. Chem. Soc. 2008, 130, 10720-10728. (c) Yu, Q.; Wang, Y.; Yi, Z.; Zu, N.; Zhang, J.; Zhang, M.; Wang, P. ACS Nano 2010, 4 (10), 6032. (d) Chiba, Y.; Islam, A.; Watanabe, Y.; Komiya, R.; Koide, N.; Han, L. Jpn. J. Appl. Phys., Part 2 2006, 45, L638-L640.

(3) Zhang, G.; Bala, H.; Cheng, Y.; Shi, D.; Lv, X.; Yu, Q.; Wang, P. Chem. Commun. 2009, 2198-2200.

(4) Zeng, W.; Cao, Y.; Bai, Y.; Wang, Y.; Shi, Y.; Zhang, M.; Wang, F.; Pan, C.; Wang, P. Chem. Mater. 2010, 22, 1915-1925.

(5) Ito, S.; Miura, H.; Uchida, S.; Takata, M.; Sumioka, K.; Liska, P.; Comte, P.; Pechy, P.; Grätzel, M. Chem Commun. 2008, 5194.

(6) Li, R.; Liu, J.; Cai, N.; Zhang, M.; Wang, P. J. Phys. Chem. B 2010, $114,4461$.

(7) Zhu, W.; Wu, Y.; Wang, S.; Li, W.; Li, X.; Chen, J.; Wang, Z.-S.; Tian, H. Adv. Funct. Mater. 2011, 21, 756.

(8) (a) Mishra, A.; Fischer, M.; Bäuerle, P. Angew. Chem., Int. Ed. 2009, 48, 2474 and references cited therein. (b) Alibabaei, L.; Kim, J.-H.; Wang, M.; Pootrakulchote, N.; Teuscher, J.; Di Censo, D.; Humphry-Baker, R.; Moser, J.-E.; Yu, Y.-J.; Kay, K.-Y.; Zakeeruddin, S. M.; Grätzel, M. Energy Environ. Sci. 2010, 3 (7), 956.

(9) Hagfeldt, A.; Boschloo, G.; Sun, L.; Kloo, L.; Pettersson, H. Chem. Rev. 2010, 110, 6595 and references cited therein.

(10) Soler, J. M.; Artacho, E.; Gale, J. D.; Garcia, A.; Junquera, J.; Ordejon, P.; Sanchez-Portal, D. J. Phys.: Condens. Matter 2002, 14, 2745-2779.

(11) Frisch, M. J. et al. Gaussian 09; Gaussian Inc.: Wallingford, CT, 2009.

(12) Chai, J.-D.; Head-Gordon, M. J. Chem. Phys. 2008, 128, 084106. 